Pacific Journal of Mathematics

MAXIMAL FUNCTIONS FOR A SEMIFLOW IN AN INFINITE
MEASURE SPACE 


\section{MAXIMAL FUNCTIONS FOR A SEMIFLOW IN AN INFINITE MEASURE SPACE}

\section{RYotaRo SATo}

Let $(X, \mathscr{F}, \mu)$ be a $\sigma$-finite measure space and $\Gamma=\left(\theta_{t}: t \geqq 0\right)$ a measurable semiflow of measure preserving transformations on $(X, \mathscr{F}, \mu)$. The maximal function $f^{*}$ of a function $f \in L_{1}(\mu)+L_{\infty}(\mu)$ is defined by

$$
f^{*}(x)=\sup _{b>0} \frac{1}{b} \int_{0}^{b}\left|f\left(\theta_{t} x\right)\right| d t .
$$

The purpose of this paper is to prove that if $\mu(X)=\infty$ and the semiflow $\Gamma$ is conservative and ergodic then for every constant $\alpha>0$

$$
\alpha \mu\left\{f^{*}>\alpha\right\}=\int_{\left\{f^{*}>\alpha\right\}}|f| d \mu .
$$

As a corollary we also prove that if $w \geqq 0$ is a constant then

$$
\int_{|| f|>t|}|f|\left(\log \frac{|f|}{t}\right)^{w+1} d \mu<\infty \text { for every } t>0
$$

if and only if

$$
\int_{\left.\mid f^{*}>t\right\}} f^{*}\left(\log \frac{f^{*}}{t}\right)^{w} d \mu<\infty \text { for every } t>0 .
$$

It is well known in ergodic theory (see e.g. [2], Chapter VIII) that if $1<p \leqq \infty$ and $f \in L_{p}(\mu)$ then $f^{*} \in L_{p}(\mu)$; while if $\mu(X)<\infty$ and $|f| \log ^{+}|f| \in L_{1}(\mu)$ then $f^{*} \in L_{1}(\mu)$. In 1979 Petersen [8] proved, under the hypothesis $\mu(X)<\infty$, that if $\left(\theta_{t}:-\infty<t<\infty\right)$ is an ergodic flow of measure preserving transformations on $(X, \mathscr{F}, \mu)$ then $f^{*} \in L_{1}(\mu)$ implies $|f| \log ^{+}|f| \in L_{1}(\mu)$. This is the continuous parameter version of Ornstein's result [7] for an invertible, ergodic and measure preserving transformation on the finite measure space. Petersen proved his result by using a reverse maximal ergodic theorem. Later, Marcus and Petersen [5] improved Petersen's maximal ergodic theorem as follows:

$$
\text { If } \mu(X)=1,0 \leqq f \in L_{1}(\mu) \text { and } \alpha \geqq \int f d \mu \text {, and if }\left(\theta_{t}:-\infty<t<\infty\right)
$$
is ergodic, then

$$
\alpha \mu\left\{f^{*}>\alpha\right\}=\int_{\left\{f^{*}>\alpha\right\}} f d \mu .
$$

(A slightly different form in which $f$ need not be nonnegative, may 
be seen in [5].) In the present paper we shall show that a similar maximal ergodic theorem holds for a conservative and ergodic semiflow $\left(\theta_{t}: t \geqq 0\right)$ on an infinite measure space, and that a ratio version of the Marcus-Petersen maximal ergodic theorem holds.

Our proof uses Derriennic's reverse maximal ergodic theorem [1], together with familiar approximation techniques. The referee has remarked that the proof given in [5] yields also our result for a conservative and ergodic flow on an infinite measure space, and then the semiflow result follows from standard extension techniques. The author thinks that the approach given below remains to be of some interest since it is more direct.

\section{Results.}

THEOREM 1. Let $\Gamma=\left(\theta_{t}: t \geqq 0\right)$ be a measurable semiflow of measure preserving transformations on a $\sigma$-finite measure space $(X, \mathscr{F}, \mu)$. Assume that $\Gamma$ is conservative and ergodic. Then the following hold:

(I) If $\mu(X)=\infty$ then for any $0 \leqq f \in L_{1}(\mu)+L_{\infty}(\mu)$ and any $\alpha>0$

$$
\alpha \mu\left\{f^{*}>\alpha\right\}=\int_{\left\{f^{*}>\alpha\right\}} f d \mu ;
$$

(II) Given $f, g \in L_{1}(\mu)$ with $f \geqq 0$ a.e. and $g>0$ a.e., define

$$
f_{g}^{*}(x)=\sup _{b>0}\left(\int_{0}^{b} f\left(\theta_{t} x\right) d t\right) /\left(\int_{0}^{b} g\left(\theta_{t} x\right) d t\right) .
$$

Then for any $\alpha>\int f d \mu / \int g d \mu$

$$
\alpha \int_{\left\{f_{g}^{*}>\alpha\right\}} g d \mu=\int_{\left\{f_{g}^{*}>\alpha\right\}} f d \mu .
$$

For the proof of the above theorem we need two lemmas. Before mentioning these, we note that the function $f_{g}^{*}$ may be defined for any $f, g \in L_{1}(\mu)+L_{\infty}(\mu)$ with $f \geqq 0$ a.e. and $g>0$ a.e. With this understanding we have the

LEMMA 1. Given $f, g \in L_{1}(\mu)+L_{\infty}(\mu)$, with $f \geqq 0$ a.e. and $g>0$ a.e., for any $\alpha>0$ we have

$$
\alpha \int_{\left\{f_{g}^{*}>\alpha\right\}} g d \mu \leqq \int_{\left\{f_{g}^{*}>\alpha\right\}} f d \mu .
$$

Proof. First suppose $0 \leqq f \in L_{1}(\mu)$. For $n \geqq 1$, let

$$
f_{n}(x)=2^{n} \int_{0}^{2^{-n}} f\left(\theta_{t} x\right) d t, \quad g_{n}(x)=2^{n} \int_{0}^{2^{-n}} g\left(\theta_{t} x\right) d t
$$


and

$$
f_{n}^{\prime}(x)=\sup _{k \geqq 0}\left(\sum_{i=0}^{k} T_{n}^{i} f_{n}(x)\right) /\left(\sum_{i=0}^{k} T_{n}^{i} g_{n}(x)\right)
$$

where $T_{n} h(x)=h\left(\theta_{2-n} x\right)$ for $h \in L_{1}(\mu)+L_{\infty}(\mu)$. Then, directly,

$$
f_{n}^{\prime} \uparrow f_{g}^{*} \text { and }\left\{f_{n}^{\prime}>\alpha\right\}=\left\{\sup _{k \geq 0} \sum_{i=0}^{k} T_{n}^{i}\left(f_{n}-\alpha g_{n}\right)>0\right\} .
$$

Since $T_{n}$ is a positive contraction on $L_{1}(\mu)$ and $\left(f_{n}-\alpha g_{n}\right)^{+} \in L_{1}(\mu)$ because $\left(f_{n}-\alpha g_{n}\right)^{+} \leqq f_{n} \in L_{1}(\mu)$, it follows from Garsia's proof (see e.g. [3], p. 23) of the Hopf maximal ergodic lemma that

$$
\int_{\left\{f_{n}^{\prime}>\alpha\right\}}\left(f_{n}-\alpha g_{n}\right) d \mu \geqq 0 .
$$

On the other hand, since $g \in L_{1}(\mu)+L_{\infty}(\mu)$, it follows from [6] that $\lim _{n} g_{n}(x)=g(x)$ a.e. Furthermore we see that $\lim _{n}\left\|f_{n}-f\right\|_{1}=$ 0. Hence, by Fatou's lemma,

$$
\begin{aligned}
\alpha \int_{\left\{f_{g}^{*}>\alpha\right\}} g d \mu & \leqq \lim _{n} \inf \alpha \int_{\left\{f_{n}^{\prime}>\alpha\right\}} g_{n} d \mu \\
& \leqq \lim _{n} \int_{\left\{f_{n}^{\prime}>\alpha\right\}} f_{n} d \mu=\int_{\left\{f_{g}^{*}>\alpha\right\}} f d \mu .
\end{aligned}
$$

Next let us consider the general case $0 \leqq f \in L_{1}(\mu)+L_{\infty}(\mu)$. Choose ${ }_{n} f \in L_{1}(\mu), n=1,2, \cdots$, so that $0 \leqq{ }_{n} f \uparrow f$. Then ${ }_{n} f_{g}^{*} \uparrow f_{g}^{*}$, and thus

$$
\begin{aligned}
\alpha \int_{\left\{f_{g}^{*}>\alpha\right\}} g d \mu & =\lim _{n} \alpha \int_{\left\{n f_{g}^{*}>\alpha\right\}} g d \mu \\
& \leqq \lim _{n} \int_{\left\{n f_{g}^{*}>\alpha\right\}} f d \mu=\int_{\left\{f_{g}^{*}>\alpha\right\}} f d \mu,
\end{aligned}
$$

which completes the proof.

LemMa 2. Let $\theta$ be a measure preserving transformation on a $\sigma$-finite measure space $(X, \mathscr{F}, \mu)$. Given $f, g \in L_{1}(\mu)+L_{\infty}(\mu)$ with $f \geqq 0$ a.e. and $g>0$ a.e., define

$$
f_{g}^{\prime}(x)=\sup _{k \geq 0}\left(\sum_{i=0}^{k} f\left(\theta^{i} x\right)\right) /\left(\sum_{i=0}^{k} g\left(\theta^{i} x\right)\right) .
$$

If $\theta$ is conservative then for any $\alpha>0$ we have

$$
\int_{\left[f_{g}^{\prime} \leqq \alpha\right] \cap\left\{f_{g}^{\prime}>\alpha\right\}} f d \mu \leqq \alpha \int_{\left[f_{g}^{\prime} \leqq \alpha\right] \cap\left(\left\{f_{g}^{\prime}>\alpha\right\} \cup \theta^{\left.\left.-1_{\left\{f_{g}^{\prime}\right.}>\alpha\right\}\right)}\right.} g d \mu
$$

where $\left[f_{g}^{\prime} \leqq \alpha\right]$ denotes the smallest $\theta$-invariant subset in $\mathscr{F}$ which contains the set $\left\{f_{g}^{\prime} \leqq \alpha\right\}$. 
Proof. See Derriennic [1]. (A minor change is sufficient for the proof.)

Proof of Theorem 1. Since the proof of (I) is similar to that of (II), we only prove (II). For $n \geqq 1$, let $f_{n}, g_{n}$ and $f_{n}^{\prime}$ be defined as in the proof of Lemma 1 . It follows that

$$
\lim _{n}\left\|f_{n}-f\right\|_{1}=0=\lim _{n}\left\|g_{n}-g\right\|_{1}
$$

and

$$
f_{n}^{\prime} \uparrow f_{g}^{*} .
$$

Denoting by ${ }_{n}\left[f_{n}^{\prime} \leqq \alpha\right]$ the smallest subset in $\mathscr{F}$ which is invariant with respect to $\theta_{2^{-n}}$ and contains the set $\left\{f_{n}^{\prime} \leqq \alpha\right\}$, we have, by Lemma 2, that

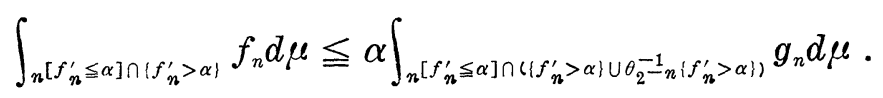

(Recall that the conservativity of the semiflow implies the conservativity of each $\theta_{t}$.) On the other hand, from an easy continuous version of Hopf's maximal ergodic lemma, we observe that

$$
\mu\left\{f_{g}^{*} \leqq \alpha\right\}>0 \text { for every } \alpha>\int f d \mu / \int g d \mu .
$$

Then the ergodicity of the semiflow implies that

$$
{ }_{n}\left[f_{g}^{*} \leqq \alpha\right] \uparrow X .
$$

and therefore

$$
\liminf _{n}\left[f_{n}^{\prime} \leqq \alpha\right]=\lim _{n}\left[f_{g}^{*} \leqq \alpha\right]=X .
$$

Consequently

$$
\int_{\left\{f_{g}^{*}>\alpha\right\}} f d \mu=\lim _{n} \int_{n\left[f_{n}^{\prime} \leqq \alpha\right] \cap\left\{f_{n}^{\prime}>\alpha\right\}} f_{n} d \mu
$$

Similarly

$$
\lim _{n} \int_{n\left[f_{n}^{\prime} \leqq \alpha\right] \cap\left(\left\{f_{n}^{\prime}>\alpha\right\} \cup \theta_{2}^{-1}-f_{n}\left\{f_{n}^{\prime}>\alpha\right\}\right)} g_{n} d \mu=\lim _{n} \int_{\left\{f_{n}^{\prime}>\alpha\right\} \cup \theta_{2}^{-1}-n\left\{f_{n}^{\prime}>\alpha\right\}} g d \mu,
$$

and let us prove that

$$
\lim _{n} \int_{\left.\left\{f_{n}^{\prime}>\alpha\right\} \cup \theta_{2}^{-1}-n \mid f_{n}^{\prime}>\alpha\right\}} g d \mu=\int_{\left.\mid f_{g}^{*}>\alpha\right\}} g d \mu .
$$

To do this, given an $\varepsilon>0$, choose $E \in \mathscr{F}$ so that 


$$
\mu(E)<\infty \text { and } \int_{X-E} g d \mu<\varepsilon .
$$

Next put $E^{\prime}=\left\{f_{g}^{*}>\alpha\right\} \cap E, E_{n}^{\prime}=\left\{f_{n}^{\prime}>\alpha\right\} \cap E$ and $E_{n}^{\prime \prime}=\left\{f_{n}^{\prime}>\alpha\right\} \cap$ $(X-E)$. It is easily seen that

$$
\begin{aligned}
& \lim _{n} \mu\left(E \Delta \theta_{2-n}^{-1} E\right)=\lim _{n}\left\|1_{E}-1_{E} \circ \theta_{2^{-n}}\right\|_{1}=0, \\
& \lim _{n} \mu\left(E^{\prime} \Delta \theta_{2-1}^{-1} E^{\prime}\right)=0, \\
& \lim _{n} \mu\left(E^{\prime}-E_{n}^{\prime}\right)=0,
\end{aligned}
$$

and

$$
\begin{aligned}
\theta_{2}^{-\frac{1}{n}} E_{n}^{\prime \prime} & \subset \theta_{2}^{-\frac{1}{1}}(X-E)=X-\theta_{2^{-1} n}^{-1} E \\
& \subset(X-E) \cup\left(E \Delta \theta_{2}^{-\frac{1}{-1}} E\right) .
\end{aligned}
$$

Hence

$$
\lim \sup _{n} \int_{\left(\theta_{2}^{-1}-n\left\{f_{n}^{\prime}>\alpha\right\}\right)-\left\{f_{n}^{\prime}>\alpha\right\}} g d \mu \leqq \int_{X-E} g d \mu<\varepsilon,
$$

and since $\varepsilon>0$ was arbitrary,

$$
\lim _{n} \int_{\left\{f_{n}^{\prime}>\alpha\right\} \cup 0_{2}^{-1}-n\left\{f_{n}^{\prime}>\alpha\right\}} g d \mu=\lim _{n} \int_{\left\{f_{n}^{\prime}>\alpha\right\}} g d \mu=\int_{\left\{f_{g}^{*}>\alpha\right\}} g d \mu,
$$

which shows that

$$
\int_{\left\{f_{g}^{*}>\alpha\right.} f d \mu \leqq \alpha \int_{\left\{f_{g}^{*}>\alpha\right\}} g d \mu .
$$

This, together with Lemma 1, completes the proof of (II).

As a corollary of Theorem 1 we obtain the following dominated ergodic theorem.

THEOREM 2. Let $\Gamma=\left(\theta_{t}: t \geqq 0\right)$ be conservative and ergodic, and let $w \geqq 0$ be a constant. Then the following hold:

( I) If $\mu(X)=\infty$ and $0 \leqq f \in L_{1}(\mu)+L_{\infty}(\mu)$, then

$$
\int_{\{f>t\}} f\left(\log \frac{f}{t}\right)^{w+1} d \mu<\infty \text { for every } t>0
$$

if and only if

$$
\int_{\left\{f^{*}>t\right\}} f^{*}\left(\log \frac{f^{*}}{t}\right)^{w} d \mu<\infty \text { for every } t>0 ;
$$

(II) Given $f, g \in L_{1}(\mu)$, with $f \geqq 0$ a.e. and $g>0$ a.e.,

$$
\int_{\{f>g\}} f\left(\log \frac{f}{g}\right)^{w+1} d \mu<\infty
$$


if and only if

$$
\int_{\left\{f_{g}^{*}>1\right\}} f_{g}^{*}\left(\log f_{g}^{*}\right)^{w} g d \mu<\infty
$$

Proof. For the proof of (I) it suffices to consider the case $t=1$. Then, by Fubini's theorem and the above theorem, we have

$$
\begin{aligned}
\int_{\left\{f^{*}>1\right\}} & f^{*}\left[\log f^{*}\right]^{w} d \mu=\int_{\left\{f^{*>1\}}\right.} \int_{1}^{f^{*}(x)}\left[(\log t)^{w}+w(\log t)^{w-1}\right] d t d \mu(x) \\
& =\int_{1}^{\infty}\left[(\log t)^{w}+w(\log t)^{w+1}\right] \mu\left\{f^{*}>t\right\} d t \\
& =\int_{1}^{\infty} \frac{1}{t}\left[(\log t)^{w}+w(\log t)^{w-1}\right] \int_{\left\{f^{*}>t\right\}} f d \mu d t \\
& \geqq \int_{1}^{\infty} \frac{1}{t}(\log t)^{w} \int_{\{f>t\}} f d \mu d t \\
= & \int_{\{f>1\}} f(x) \int_{1}^{f(x)} \frac{1}{t}(\log t)^{w} d t d \mu(x) \\
= & \frac{1}{w+1} \int_{\{f>1\}} f(\log f)^{w+1} d \mu
\end{aligned}
$$

On the other hand, Lemma 1 together with a standard argument gives

$$
\mu\left\{f^{*}>t\right\} \leqq \frac{2}{t} \int_{\mid f>t / 2\}} f d \mu \text { for every } t>0,
$$

thus

$$
\begin{aligned}
\int_{\left\{f^{*}>1\right\}} & f^{*}\left[\log f^{*}\right]^{w} d \mu \\
& \leqq \int_{1}^{\infty} \frac{2}{t}\left[(\log t)^{w}+w(\log t)^{w-1}\right] \int_{\{f>t / 2\}} f d \mu d t \\
& =\int_{\{2 f>1\}} 2 f\left[(w+1)^{-1}(\log 2 f)^{w+1}+(\log 2 f)^{w}\right] d \mu,
\end{aligned}
$$

and the last integral is finite if the first condition of (I) is satisfied. So (I) is proved.

The proof of (II) may be done similarly and omitted.

REMARK. The linear subclasses $R_{w}(\mu), w \geqq 0$, of $L_{1}(\mu)+L_{\infty}(\mu)$ defined by

$$
R_{w}(\mu)=\left\{f: \int_{|| f \mid>t\}}|f|\left(\log \frac{|f|}{t}\right)^{w} d \mu<\infty \text { for all } t>0\right\}
$$

were originally introduced by Fava [3] in order to obtain a weak 
type inequality for a product of maximal operators. In view of [3], [6] and [10], these subclasses are important in pointwise ergodic theory.

\section{REFERENCES}

1. Y. Derriennic, On the integrability of the supremum of ergodic ratios, Ann. probability, 1 (1973), 338-340.

2. N. Dunford and J. T. Schwartz, Linear Operators. I: General Theory, Interscience, New York, 1958.

3. N. A. Fava, Weak type inequalities for product operators, Studia Math., 42 (1972), 271-288.

4. A. M. Garsia, Topics in Almost Everywhere Convergence, Markham, Chicago, 1970.

5. B. Marcus and K. Petersen, Balancing ergodic averages, Ergodic Theory (Proceedings, Oberwolfach, 1978), Springer Lecture Notes in Math., No. 729, pp. 126-143, Springer, Berlin-Heidelberg-New York, 1979.

6. S. A. McGrath, Local ergodic theorems for noncommuting semigroups, Proc. Amer. Math. Soc., 79 (1980), 212-216.

7. D. Ornstein, A remark on the Birkhoff ergodic theorem, Illinois J. Math., 15 (1971), 77-79.

8. K. Petersen, The converse of the dominated ergodic theorem, J. Math. Anal. Appl., 67 (1979), 431-436.

9. R. Sato, Two local ergodic theorems on $L_{\infty}$, J. Math. Soc. Japan, 32 (1980), 415-423.

10. R. Sato, Ergodic theorems for d-parameter semigroups of Dunford-Schwartz operators, Math. J. Okayama Univ. 23 (1981), 41-57.

Received August 20, 1980.

Okayama University

ОкаYаMA

700 JAPAN 



\section{PACIFIC JOURNAL OF MATHEMATICS}

\section{EDITORS}

DONALD BABBITT (Managing Editor)

University of California

Los Angeles, CA 90024

Hugo RossI

University of Utah

Salt Lake City, UT 84112

C. C. Moore and Arthur Agus

University of California

Berkeley, CA 94720
J. DugundJI

Department of Mathematics

University of Southern California

Los Angeles, CA 90007

R. FinN and J. MiLgRAM

Stanford University

Stanford, CA 94305

\section{ASSOCIATE EDITORS}
R. ARENS
E. F. BECKENBACH
B. H. NeumanN
F. WOLF
K. YoSHIDA

\section{SUPPORTING INSTITUTIONS}

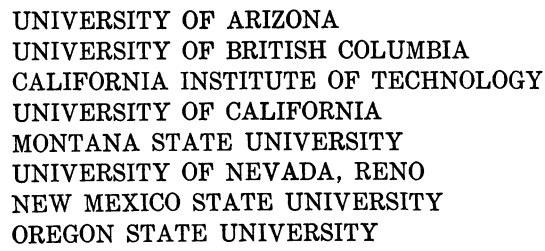

UNIVERSITY OF ARIZONA

UNIVERSITY OF BRITISH COLUMBIA CALIFORNIA INSTITUTE OF TECHNOLOGY UNIVERSITY OF CALIFORNIA MONTANA STATE UNIVERSITY

UNIVERSITY OF NEVADA, RENO NEW MEXICO STATE UNIVERSITY OREGON STATE UNIVERSITY

\author{
UNIVERSITY OF OREGON \\ UNIVERSITY OF SOUTHERN CALIFORNIA \\ STANFORD UNIVERSITY \\ UNIVERSITY OF AAWAII \\ UNIVERSITY OF TOKYO \\ UNIVERSITY OF UTAH \\ WASHINGTON STATE UNIVERSITY \\ UNIVERSITY OF WASHINGTON
}

The Supporting Institutions listed above contribute to the cost of publication of this Journal, but they are not owners or publishers and have no responsibility for its content or policies,

Mathematical parers intended for publication in the Pacific Journal of Mathematics should be in typed form or offset-reproduced, (not dittoed), double spaced with large margins. Please do not use built up fractions in the text of the manuscript. However, you may use them in the displayed equations. Underline Greek letters in red, German in green, and script in blue. The first paragraph or two must be capable of being used separately as a synopsis of the entire paper. Please propose a heading for the odd unmbered pages of less than 35 characters. Manuscripts, in triplicate, may be sent to any one of the editors. Please classify according to the scheme of Math. Reviews, Index to Vol. 39. Supply name and address of author to whom proofs should be sent. All other communications should be addressed to the managing editor, or Elaine Barth, University of California, Los Angeles, California, 90024 .

50 reprints to each author are provided free for each article, only if page charges have been substantially paid. Additional copies may be obtained at cost in multiples of 50 .

The Pacific Journal of Mathematics is issued monthly as of January 1966, Regular subscription rate: $\$ 114.00$ a year (6 Vol., 12 issues). Special rate: $\$ 57.00$ a year to individual members of supporting institution.

Subscriptions, orders for numbers issued in the last three calendar years, and changes of address shoud be sent to Pacific Journal of Mathematics, P.O. Box 969, Carmel Valley, CA 93924, U.S.A. Old back numbers obtainable from Kraus Periodicals Co., Route 100, Millwood, NY 10546.

\section{PUBLISHED BY PACIFIC JOURNAL OF MATHEMATICS, A NON-PROFIT CORPORATION}

Printed at Kokusai Bunken Insatsusha (International Academic Printing Co., Ltd.). 8-8, 3-chome, Takadanobaba, Shinjuku-ku, Tokyo 160, Japan.

Copyright (C) 1982 by Pacific Journal of Mathematics Manufactured and first issued in Japan 


\section{Pacific Journal of Mathematics}

Vol. 100, No. $2 \quad$ October, 1982

Kenneth F. Andersen, On the transformation of Fourier coefficients of

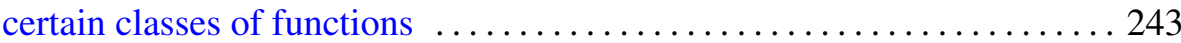

Steven Albert Bleiler, Realizing concordant polynomials with prime knots

Reinhard Bürger, Functions of translation type and solid Banach spaces of functions

Ulrich Daepp, The saturation of $k$-analytic rings and topological equivalence of associated analytic set germs .................. 271

Persi W. Diaconis and David Amiel Freedman, On the maximum difference between the empirical and expected histograms for sums . . . 287

David Amiel Freedman, On the maximum of scaled multinomial

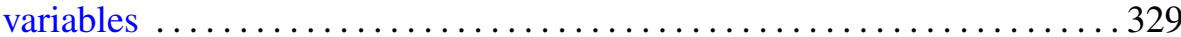

Persi W. Diaconis and David Amiel Freedman, On the difference between the empirical histogram and the normal curve, for sums. II ......... 359

Persi W. Diaconis and David Amiel Freedman, On the mode of an

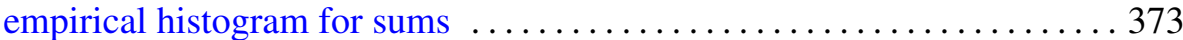

Jutta Hausen, Supplemented modules over Dedekind domains 387

Elyahu Katz, A moduli representation for the classification of twisted tensor

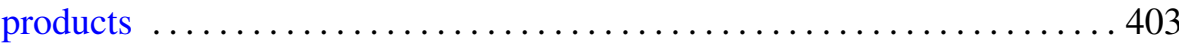

H. C. Madhekar and N. K. Thakare, Biorthogonal polynomials suggested by the Jacobi polynomials

Ted R. Pettis, Collections of covers of metric spaces 425

Ryōtarō Satō, Maximal functions for a semiflow in an infinite measure space

Michael Jay Stob, Invariance of properties under automorphisms of the lattice of recursively enumerable sets 